\title{
A Inserção do Curso de Técnico em Saúde Bucal na Policlínica Piquet Carneiro
}

The insertion of the Dental Hygienist Course at the Policlínica Piquet Carneiro

\section{Introdução}

Os serviços de saúde bucal vêm experimentando profundas transformações a partir da segunda metade do século XX. A discrepância entre o número de pessoas com necessidade de assistência odontológica frente à má distribuição de profissionais e a possibilidade de melhorar as condições de saúde bucal da população por meio de procedimentos preventivos teve influência na deliberação de políticas públicas educacionais na década de $1970^{1}$.

Embora a utilização de pessoal de nível elementar e médio no serviço público, no Brasil, tenha se iniciado no final da década de 1970, é nas décadas de 1980 e 1990 que sofre uma considerável expansão, decorrente do movimento de Reforma Sanitária. De acordo com Narvai ${ }^{2}$, nesta época destacou-se a incorporação de sistemas de trabalho inovadores decorrentes da aplicação de princípios ergonômicos ao processo odontológico, as novas exigências de biossegurança e, principalmente medidas de promoção de saúde, tanto individuais quanto coletivas.

Assim, os Técnicos em Saúde Bucal, anteriormente denominados Técnicos em Higiene Dental começaram a fazer parte de equipe de odontologia. Com o passar dos anos a odontologia mudou seu foco de atuação, vivendo hoje sob o paradigma de promoção da saúde. A inserção do técnico no mercado de trabalho tem sido ampliada por conta das políticas públicas voltadas para a saúde bucal desde o início da década de 2000, tendo o Sistema Único de Saúde - SUS como principal empregador. A profissão alcançou regulamentação no ano de 2008, por meio da Lei no. 11.889, e sua formação não poderia deixar de acompanhar tais mudanças ${ }^{3}$.

O curso de Técnico em Saúde Bucal (TSB) ministrado pela Faculdade de Odontologia da Uni-
Andrea Lanzillotti Cardoso', Fernanda Barja-Fidalgo ${ }^{2}$, Maria Isabel de Castro Souza ${ }^{3}$, Urubatan Vieira de Medeiros ${ }^{4}$, Maria Rita dos Santos Ritto 5 e Luciana Freitas Bastos ${ }^{6}$.

\section{Resumo}

No Brasil, o Técnico em Saúde Bucal (TSB) é uma categoria auxiliar no campo da saúde bucal criada o final da década de 1970, que sofreu uma considerável expansão com o atual modelo adotado pela odontologia, baseado na promoção de saúde, e com as políticas públicas de saúde bucal vigentes no país. Nesse contexto, o Sistema Único de Saúde (SUS) atualmente é o principal empregador do Técnico em Saúde Bucal. O objetivo do nosso artigo é o de descrever a experiência da implantação do estágio extramuros do curso de formação de TSB no serviço de Odontologia da Policlínica Piquet Carneiro. Essa parceria tem oportunizado imersão pelos alunos em cenários de prática que se traduzem num espaço privilegiado e os aproximam tanto de uma equipe multiprofissional quanto das demandas reais do processo de trabalho, gerando benefícios diretos para a formação dos alunos e para o fluxo do serviço, bem como uma melhor assistência ao usuário. Assim, este estágio extensionista encontra numa unidade multidisciplinar do SUS a oportunidade da integração entre teoria e prática e, consequentemente, conduz a formação de TSBs às competências exigidas para os profissionais que atuam no sistema público de saúde.

Palavras-chave: Odontologia; Serviço de Saúde Bucal /Recursos Humanos; Odontologia em Saúde Pública

Área Temática: Saúde

Linha de Extensão: Saúde Humana

' Doutora em Saúde Pública. ENSP/FIOCRUZ. E-mail: andrealanzi.ppc@ gmail.com

${ }^{2}$ Doutora em Ciências da Saúde. UERJ. E-mail: fbarja@gmail.com

3 Doutora em Odontologia. UFRJ. E-mail: profamariaisabel@yahoo.com.br

${ }^{4}$ Doutor em Odontologia. USP. E-mail: umedeiros@globo.com

5 Técnica em Saúde Bucal. UERJ. E-mail: ritarthd@gmail.com

${ }^{6}$ Doutora em Odontologia. UFRJ. E-mail: lucianafreitasbastos@yahoo.com 
versidade do Estado do Rio de Janeiro (F.O.UERJ) teve início na década de 1970 e esse relato pretende contar um pouco sobre a história deste curso técnico e em especial as mudanças realizadas com a saída do curso para as atividades extramuros em 2008, em resposta às demandas contemporâneas que surgem para a formação de profissionais de saúde, com a formação de alunos inseridos no serviço, se apropriando do processo de trabalho no SUS e para o SUS.

\section{O curso de formação de TSB da FOUERJ}

O curso de formação de técnico em Saúde Bucal da Faculdade de Odontologia da UERJ teve inicio em 1975, com aulas teóricas e estágio prático dentro das dependências da própria faculdade, com duração de dois anos em tempo integral. No início dos anos 1980, adotou-se uma nova abordagem com maior ênfase às ações coletivas e o curso passou a ter os estágios práticos extramuros, que iniciaram na clínica odontológica do Colégio de Aplicação da UERJ (CApUERJ) e em uma clínica volante, que percorria escolas municipais em parceria com a prefeitura do município do Rio de Janeiro.

No final da década de 1980, por questões logísticas o curso mudou novamente sua estrutura e deixa de oferecer o estágio extramuros na clínica volante, sendo este fixado em duas clínicas montadas em escolas públicas pela F.O.UERJ, quais sejam: o CApUERJ e a Escola Municipal República Argentina (ERA). Em meados dos anos 1990, a clínica do CApUERJ foi desativada e o estágio prático, assim como as aulas teóricas se concentraram na ERA.

No final dos anos 1990 houve nova reformulação do curso, que deixou de ser ministrado em período integral e passou a ser oferecido em meio período, com duração de dois anos; uma vez que se observou que grande parte dos alunos que se submetiam ao curso, já trabalhavam na área como auxiliar de saúde bucal e buscavam aperfeiçoamento.

\section{A parceria de sucesso entre o curso de formação de TSB e o setor de odontologia da Policlínica Piquet Carneiro}

A Policlínica Piquet Carneiro - PPC, unidade do Centro Biomédico da UERJ, desde 2005, passou a ser campo de estágio opcional para os alunos. Esta instituição presta serviços de saúde à população atuando de forma integrada com diversas faculdades da universidade, como odontologia, medicina, enfermagem, nutrição e serviço social; no desenvolvimento do ensino, da pesquisa e da extensão.

O início da gestão da PPC pela UERJ no ano 2008 e a indicação da coordenação para as respectivas clínicas impactou especialmente no setor de odontologia e desencadeou um maior estímulo para que o estágio extramuros do curso de formação de TSB fosse realizado na PPC. Desde então, com uma nova abordagem, os alunos do curso de TSB têm a oportunidade não só de assistir aos alunos e profissionais do serviço, denominado trabalho à quatro mãos; como detêm uma clinica específica para sua própria atuação em assistência individual, ou mesmo têm a oportunidade de manipular materiais e desenvolver prática no âmbito administrativo e de esterilização. Ademais, proporcionando uma visão mais ampla de promoção de saúde, os alunos têm a oportunidade de atuar, em ações coletivas multidisciplinares, junto a diversos profissionais (médicos, enfermeiros e nutricionistas), voltado às reais necessidades da população e permitindo aos alunos uma integração entre prática e teoria.

O estágio realizado na PPC oferece aos alunos uma experiência multidisciplinar vivenciando a realidade do serviço público, com a oportunidade de atuar nas diferentes situações que a profissão exige. Assim, respeitando um cronograma de tarefas, os alunos tramitam por todos os setores da clínica de odontologia.

Vale ressaltar que os alunos do curso de TSB atuam como contato inicial do usuário com as orientações de promoção de saúde oral, ainda fora do setor de odontologia, e continua o acompanhamento deste, motivando-o a cada consulta com orientações específicas. Desse modo, a presença do curso nas dependências da PPC contribui com a agilidade do serviço, permitindo um maior fluxo de atendimentos dentro do setor.

Em 2012, o curso deu início a uma nova fase, a semipresencial, com vistas a atender a atual necessidade dos alunos e manter a qualidade que o afamou. Dessa maneira, o curso passou a ser ministrado em dois semestres. No primeiro é oferecido toda a carga teórica, nos moldes dos cursos de en- 
sino à distância (EAD), com uma aula presencial em cada módulo. No segundo semestre, ocorre o estágio prático, no setor de odontologia da PPC.

Essas mudanças realizadas nos últimos anos só foram possíveis com a parceira da coordenação do curso com a PPC, sendo essenciais para a formação de profissionais qualificados que respondem às demandas contemporâneas, permitindo que os seus alunos atuem em um serviço odontológico de vanguarda situado na Policlínica Piquet Carneiro.

\section{Considerações finais}

Estamos certos que a implementação do estágio extramuros na PPC está contribuindo não só com a melhor formação dos alunos do curso de formação em TSB, mas também com a melhora das condições bucais dos usuários da PPC, o aumento no fluxo de atendimento no setor e na ação coletiva de promoção de saúde que é sistematicamente realizada nas diversas salas de espera da PPC; e que $\mathrm{faz}$ de seus espectadores, disseminadores dos saberes apreendidos em palestras realizadas enquanto os usuários aguardam por atendimento médico.

Esta experiência extramuros vai ao encontro do que está disposto na Política Nacional de Extensão ${ }^{4}$ vigente no país, que determina que o trabalho extensionista seja entendido como uma relação de mão-dupla, onde há possibilidade de aproximação, integração e parceria da academia com a sociedade. Considerando que a extensão é a oportunidade da integração entre teoria e prática, por meio da interdisciplinaridade, a parceria do curso de formação de TSB e do serviço de odontologia da PPC é uma experiência que pode ser seguida por outros cursos de nível técnico e vem trazendo real beneficio tanto para a formação dos alunos do curso de TSB como para o serviço odontológico prestado para a sociedade.

\section{Referências}

1. OLIVEIRA, J. A. A. O Técnico de Higiene Bucal: trajetória e tendências de profissionalização com vista ao maior acesso aos serviços de saúde bucal. [Dissertação de Mestrado]. Rio de Janeiro: ENSP/FIOCRUZ, 2007.

2. NARVAl, P. C. Recursos humanos para promoção em saúde bucal. In: KRIGER, L. (org). Promoção de saúde bucal ABOPREV. São Paulo: Ed. Artes médicas, 1997. p. 448-463.

3. BRASIL. Lei no. 11.889, de 24 de dezembro de 2008. Regulamenta o exercício das profissões de Técnico em Saúde Bucal - TSB e de Auxiliar em Saúde Bucal - ASB.

4. BRASIL. Ministério da Educação. Secretaria de Educação Superior. Extensão Universitária: Organização e Sistematização. Política Nacional de Extensão. Universidade Federal de Minas Gerais. PROEX. COOPMED Editora, 2007. Disponível em: <http://proex.ufpa.br/DIRETORIO/DOCUMENTOS/PROEX/02pnext.pdf> 